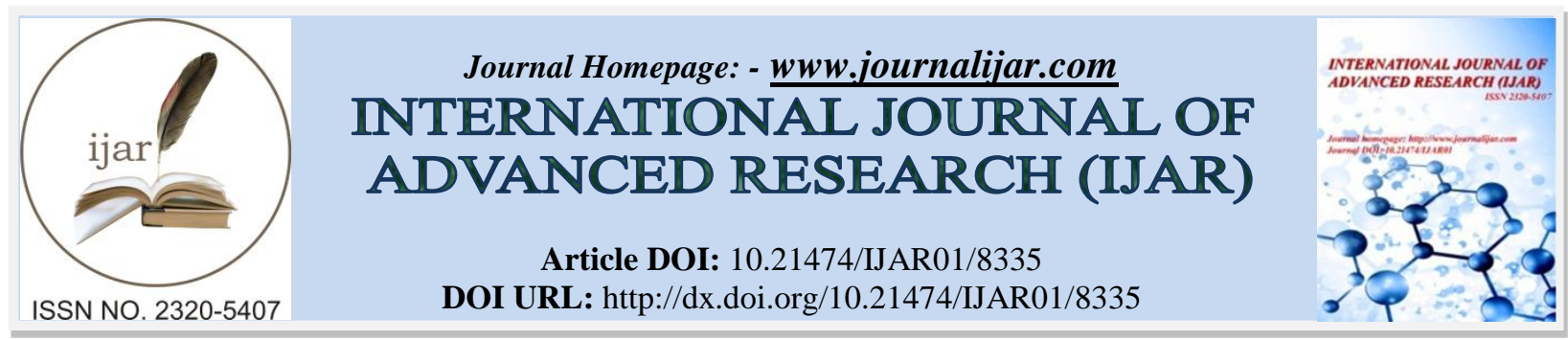

RESEARCH ARTICLE

\title{
MANAGEMENT OF SEPARATED INSTRUMENTS WITHIN ROOT CANALS.
}

\section{S.Vyshakh ${ }^{1}$, K. Harish S. Shetty ${ }^{2}$, Sreegowri Bhat ${ }^{3}$ and Nishi Jayasheelan ${ }^{4}$.}

1. Post graduate student, Department Of Conservative Dentistry And Endodontics, Yenepoya Dental College, Yenepoya University, Deralakatte, Mangaluru, Karnataka -575018.

2. Senior Professor and HOD, Department Of Conservative Dentistry And Endodontics, Yenepoya Dental College, Yenepoya University, Deralakatte, Mangaluru, Karnataka -575018.

3. Reader, Department Of Conservative Dentistry And Endodontics, Yenepoya Dental College, Yenepoya University, Deralakatte, Mangaluru, Karnataka -575018.

4. Senior lecturer, Department Of Conservative Dentistry And Endodontics, Yenepoya Dental College, Yenepoya University, Deralakatte, Mangaluru, Karnataka -575018 .

\section{Manuscript Info}

Manuscript History

Received: 08 November 2018

Final Accepted: 10 December 2018

Published: January 2019

Key words:-

Separatd,instruments,fileretriev alseparted file bypass.

\begin{abstract}
Mechanical debridement of the microorganisms from root canal and thorough cleaning is the primary goal of a root canal treatment. Metallic instruments including manual and rotary files facilitate clinician to achieve this goal. Introduction of stainless steel and nickel titanium instruments have made a breakthrough in endodontics by saving the chair side time. In spite of this advantage, it has got a major drawback of separation too. Separation of instrument is a nightmare for all the clinicians. But having known the ways of overcoming this hurdle, it becomes easy to manage such cases. Various retrieval systems introduced in the market facilitates ease of removal of separated instrument. This article reviews the various instrument retrieval systems and the use of ultrasonics in retrieving separated instruments from the root canal.
\end{abstract}

Copy Right, IJAR, 2018,. All rights reserved.

\section{Introduction:-}

Endodontists in their clinical routine deal with many procedures from root canal therapy to surgical techniques like apicectomy, hemisection etc. and one of the most challenging case is the retreatment of root canal treated teeth with a separated instrument. The removal of separated instruments from root canals are very difficult and at times can be impossible, with a reported success rate ranging from 55 to 79\% [1]. Lot of techniques and devices for retrieving the separated instrument fragment have been described in the literature with most successful method being the use of ultrasonics along with a dental operating microscope[2,3].

Bypassing the instrument is a conservative technique while surgical management is a more radical technique which requires osteotomy and root resection[4]. The other procedure is the retrieval of the instrument from the canal[5]. The present article is intended to give a review of different techniques for separated file removal and various ways to prevent it from happening.

Corresponding Author:-S.Vyshakh.

Address:-Post graduate student, Department Of Conservative Dentistry And Endodontics, Yenepova Dental College. Yenenova Universitv. Deralakatte. Mangaluru. Karnataka -575018. 


\section{Tips To Avoid Instrument Separation In Endodontic The canal should be lubricated}

One should never insert a file into a dry canal, and in order to guarantee wetting of canal the pulp chamber is soaked with sodium hypochlorite. Debris is kept in fluid suspension (in theory) and the sodium hypochlorite acts as a lubricant[6]. EDTA $17 \%$ is a good lubricating agent which would help the files to glide through the canals without much strain.

\section{Single use of hand files and rotary instruments}

Partially fatigued instruments, when flexed, will reveal fractures associated with surface flaws, and prolonged clinical use of rotary NiTi instruments significantly reduces their cyclic flexural fatigue resistance. But the number of uses of rotary NiTi instruments will depend on a number of variables, including instrument properties, canal morphology and operator skill[5]. During sterilization the files undergo cyclic fatigue[7,8,9]. The file surface turn to be rougher after each sterilization[10]. This is because of the protective oxide layer forming over the instrument. As roughness increases the cutting efficiency decreases. The NiTi files are usually made through milling procedures, as a results microcracks will be present on the file surface. During shaping of the canals a lot of stress is being transferred to the files and as a result the micro cracks grow in size and lead to file separation. According to a study conducted ProTaper rotary files may be safely reused at least four times[11] but the rotary files usually show defects by torsional fatigue when reused[12,13].

\section{Cleaning instrument flutes during instrumentation of the root canal}

Use of an endodontic sponge (SybronEndo) will assist with debris removal, thus avoiding debris accumulation on the file and allowing the file flutes to refill with debris between each individual canal instrumentation[6].

\section{Obtain complete working length patency}

Complete working length patency should be obtained with the help of hand files to create a pathway into the canal. This would help the rotary files to glide into the canals without much strain.

\section{Using hand instruments followed by rotary}

Using hand instruments in a step back motion followed by rotary in crown down technique reduced the chances of file separation[14,15].

\section{Treatment Planning}

Treatment for a separated instrument varies from case to case depending on the size and length of the separated file, nature of separated file, position of separated file, shape of the canal, cross section of the canal and other factors like the condition of the tooth, the age of the patient etc. When it comes to a separated instrument the size, length and position of the canal plays a major role. Longer the instrument the tougher it is to retrieve the instrument. The design of the flutes also plays a major role for eg. $\mathrm{H}$ files due to its inverted Christmas tree shape adheres to dentine more compared to $\mathrm{k}$ files. The position of the file is one of the major factors in determining the way of treatment. If the separated file is in the apical one third, retrieval of the file becomes quiet difficult and would result excess removal of dentine so bypassing the file is a better option. If the separated file is at the apical tip, obturating the canal just over the separated file is the best option. If bypassing of file is performed at the apex it might push the file beyond the apex. If the file is partially or fully beyond the apex it requires a periapical surgery of its retrieval.

The canal cross-section of the tooth also plays a major role, its easier to bypass an elongated or oval canal when compared to a round canal as there will be a lot of space present in between the separated file and dentine interface[16].

\section{Retrieval Kits}

All the retrieval kits work in common principle of loosening the separated instrument followed by its removal using ultrasonic energy, loupes, steiglitz forceps or wrench and tube. The rotary files acts like a screw which drills itself into dentin in rotating motion. When the file gets separated, it gets stuck into the dentine. To retrieve the file the dentine adjacent to the file should be removed to loosen up this file. The most common complication reported was the excessive removal of tooth structure. This process can reduce root strength by $30-40 \%$ and may predispose the tooth to vertical root fracture[17]. Therefore the success of the file retrieval also depends on the minimum amount of removal of circumferential dentine. 


\section{Terauchi File Retrieval Kit}

It consists of FRK-T(trephine bur), GGB3(modified gates glidden bur), FRK-S(straight ultrasonic tip), FRK6(spoon shaped ultrasonic tip), FRK-12, teraushi loops, microexplorer, gutta percha remover[18].

Modified gates glidden burs are used to get a straight line access for better visibility and working. Trephine burs help in removing the dentine around the coronal 1 to $2 \mathrm{~mm}$ of separated file. The FRK-S and FRK-6, FRK-12 are ultrasonic tips used to remove the cirumferential dentine. Loupes are used to remove longer separated files. Longer separated files cannot pop out of the canal with the ultrasonic energy alone, so they are removed using loops after loosening it within the canal[18].

\section{Instrument Retrieval System (Irs Kit)}

It consists of core drills and instrument retrieval kit. The core drills help in removing the circumferential dentine and loosen up the separated file. They are hand operated tube like drills with a cutting tip and a handle. They are used in clockwise motion.

The main element in this is the microtube and screw wedge. The microtube is carefully placed over the separated file and the screw wedge is tightened in counter clockwise direction. When the tube and screw wedge is tightened the separated file get entangled in between and it can be easily removed from the canal.

\section{Masserann Kit}

The kit consists of a series of trephining drills and 2 sizes of tubular extractors $(1.2 \mathrm{~mm}, 1.5 \mathrm{~mm})$. A space is created around the coronal $2 \mathrm{~mm}$ of the separated instrument. Extractor tube passes over it and extractor plunger is screwed down locking the object[19, 20,21].

\section{Endo Extractor Kit (Brasseler)}

Includes 4 sizes of trephine burs. Cyanoacrylate adhesive is used to bond hollow tube to separated file. Time required to set $5 \mathrm{~min}$ to $10 \mathrm{~min}$.

\section{Ultrasonics In Endodontics}

Ultrasonics play a major role in removal of separated files. Ultrasonics help in removing the circumferential dentine around the file and help in loosening it. The use of ultrasonic should be done under an operative microscope to improve the quality of work. Using coolant like water under ultrasonic procedures can reduce visibility and might result in excessive cutting of the dentin. The ultrasonic should be used in an intermittent manner to reduce the heat produced within the canal. Studies have shown that using ultrasonics for longer intervals result in heat production which can cause damage to the periodontal ligament as well as result in bone resorption[22].

There are various types of ultrasonic tips available for the removal of separated instruments. The thinner the tips the lesser the dentine removed from the canal walls. Every file separated in the canal has an inner and outer surface. Always the inner surface should be activated with ultrasonics as it pushes the file outwards. While on the other hand, activating the ultrasonic tip at the outer surface pushes the separated file further into the canal. The inward and outward surfaces should be noted with the help of x-rays and cbct before using ultrasonics.

The anatomy of the tooth should be noted before using ultrasonics. The position of the file and the curvatures of the root should be well observed[23]. The danger zones ie. the thin zones of dentine should be carefully treated with ultrasonics as it can result in perforations or thin walls .

\section{Conclusion:-}

Although a lot of techniques[24-30] and retrieval kits are out in the market a lot of practice and experience is required to master the skill of retrieval of instruments. The retrieval of the instrument should be done with minimal dentine removal. Preserving the dentine is the most important thing as it determines the longevity of the tooth. Perforations or thinned walls can reduce the longevity of teeth. Simply discarding all instruments after the completion of each endodontic case will reduce breakage, lost clinical time and upsets. 


\section{Reference:-}

1. Hülsmann M, Schinkel I. (1999): Influence of several factors on the success or failure of removal of fractured instruments from the root canal. Dental Traumatology,15(6):252-8.

2. Plotino G, Pameijer CH, Grande NM, Somma F. (2007): Ultrasonics in endodontics: a review of the literature. Journal of endodontics, 1;33(2):81-95.

3. Cujé J, Bargholz C, Hülsmann M. (2010): The outcome of retained instrument removal in a specialist practice. International endodontic journal,43(7):545-54.

4. Arunagiri D, Misra A, Singh A, Kapoor S. (2015): Retrieval of Separated Instruments: A Case Series Part II. Rama Uni J Dent Sci.;2(2):31-4.

5. Ruddle CJ. (2002): Broken instrument removal: the endodontic challenge. Dentistry today,21(7):70-81.

6. Mullane E. (2015): Tips to avoid instrument separation in endodontics. Irish Dental Association.

7. Ullmann CJ, Peters OA. (2005): Effect of cyclic fatigue on static fracture loads in ProTaper nickel-titanium rotary instruments. Journal of Endodontics, 1;31(3):183-6.

8. Li UM, Lee BS, Shih CT, Lan WH, Lin CP. (2002): Cyclic fatigue of endodontic nickel titanium rotary instruments: static and dynamic tests. Journal of endodontics, 1;28(6):448-51.

9. Fife D, Gambarini G, Britto LR. (2004): Cyclic fatigue testing of ProTaper NiTi rotary instruments after clinical use. Oral Surgery, Oral Medicine, Oral Pathology, Oral Radiology, and Endodontology, 1;97(2):251-6.

10. Nair AS, Tilakchand M, Naik BD. (2015); The effect of multiple autoclave cycles on the surface of rotary nickel-titanium endodontic files: An in vitro atomic force microscopy investigation. Journal of conservative dentistry, JCD.;18(3):218.

11. Wolcott S, Wolcott J, Ishley D, Kennedy W, Johnson S, Minnich S, Meyers J. (2006): Separation incidence of protaper rotary instruments: a large cohort clinical evaluation. Journal of endodontics, 1;32(12):1139-41.

12. Chakka NV, Ratnakar P, Das S, Bagchi A, Sudhir S, Anumula LD. (2012): NiTi instruments show defects before separation? Defects caused by torsional fatigue in hand and rotary nickel-titanium (NiTi) instruments which lead to failure during clinical use. J Contemp Dent Pract. 1;13(6):867-72.

13. Cheung GS, Peng B, Bian Z, Shen Y, Darvell BW. (2005): Defects in ProTaper S1 instruments after clinical use: fractographic examination. International Endodontic Journal,38(11):802-9.

14. Roland DD, Andelin WE, Browning DF, Hsu GH, Torabinejad M. (2002): The effect of preflaring on the rates of separation for 0.04 taper nickel titanium rotary instruments. Journal of Endodontics, 1;28(7):543-5.

15. Patiño PV, Biedma BM, Liébana CR, Cantatore G, Bahillo JG. (2005); The influence of a manual glide path on the separation rate of NiTi rotary instruments. Journal of Endodontics, 1;31(2):114-6.

16. Madarati AA, Hunter MJ, Dummer PM. (2013): Management of intracanal separated instruments. Journal of endodontics, 1;39(5):569-81.

17. Wadhawan R, Luthra K, Sidhu JK, Solanki G. Are you ready to overpower the challenge of instrument separation in endodontics: a review.

18. Terauchi Y, O’Leary L, Suda H. (2006): Removal of separated files from root canals with a new file-removal system. Journal of endodontics, 1;32(8):789-97.

19. Pai AV, Mir S, Jain R. (2013): Retrieval of a metallic obstruction from the root canal of a premolar using Masserann technique. Contemporary clinical dentistry,4(4):543.

20. Okiji T.(2003):Modified usage of the Masserann kit for removing intracanal broken instruments. Journal of endodontics, 1;29(7):466-7.

21. Yoldas O, Oztunc H, Tinaz C, Alparslan N. (2004):Perforation risks associated with the use of Masserann endodontic kit drills in mandibular molars. Oral Surgery, Oral Medicine, Oral Pathology, Oral Radiology, and Endodontology,1;97(4):513-7.

22. Walters JD, Rawal SY. (2007):Severe periodontal damage by an ultrasonic endodontic device: a case report. Dental Traumatology,23(2):123-7.

23. Plotino G, Pameijer CH, Grande NM, Somma F.(2007): Ultrasonics in endodontics: a review of the literature. Journal of endodontics, 1;33(2):81-95.

24. Karimi Z, Chala S, Sakout M, Abdallaoui F.(2017): Strategies for intracanal separated instrument removal: a review. Dental Update,2;44(7):636-46.

25. Al-Zahrani M, Al-Nazhan S.(2012): Retrieval of separated instruments using a combined method with a modified vista dental tip. Saudi Endodontic Journal, 1;2(1):41-.

26. do Prado M, Gusman HC. Removal of a silver cone by using clinical microscope and ultrasound: Case report.

27. Rahimi M, Parashos P.(2009): A novel technique for the removal of fractured instruments in the apical third of curved root canals. International endodontic journal,42(3):264-70. 
28. Ormiga F, Gomes JA, de Araújo MC.(2010): Dissolution of nickel-titanium endodontic files via an electrochemical process: a new concept for future retrieval of fractured files in root canals. Journal of endodontics, $1 ; 36(4): 717-20$.

29. Aboud LR, Ormiga F, Gomes JA.(2014): Electrochemical induced dissolution of fragments of nickel-titanium endodontic files and their removal from simulated root canals. International endodontic journal.;47(2):155-62.

30. Ruddle CJ.(2004): Nonsurgical retreatment. Journal of Endodontics, 1;30(12):827-45. 